Supporting Information for

\title{
Maximizing impeller power efficiency in gas-solid-liquid stirred vessels through process intensification
}

\author{
Meysam Davoody ${ }^{\mathrm{a}}$, Abdul Aziz Bin Abdul Raman ${ }^{\mathrm{a}}$, Rajarathinam Parthasarathy ${ }^{* b}$
}

a: Department of Chemical Engineering, Faculty of Engineering, University of Malaya,

50603 Kuala Lumpur, Malaysia

b: School of Civil, Environmental, and Chemical Engineering, RMIT University, City Campus, Melbourne, VIC 3001, Australia

Meysam Davoody

Tel: +6 0172889246

meysam.davoody@rmit.edu.au

Abdul Aziz Abdul Raman

Tel: +60 379675300 ,

Fax: +60 379675319

azizraman@um.edu.my

Rajarathinam Parthasarathy

Tel: + 61399252941

Fax: + 61399252941

rchrp@rmit.edu.au

* Corresponding author. Tel.: + 6139925 2941; E-mail address: $\underline{\text { rchrp@ @rmit.edu.au }}$

Postal address: School of Civil, Environmental, and Chemical Engineering, RMIT University, City Campus, Melbourne VIC 3001, Australia 
Figure S1. Specifications of the setup depicted in Figure 2

\begin{tabular}{llcl}
\hline Labe & Details & Label & Details \\
I & & & \\
\hline A & Pulley & J & Level sensor \\
B & Bearings & $\mathrm{K}$ & Tachometer \\
C & Motor & $\mathrm{M}$ & Counterweight \\
D & Impeller diameter & $\mathrm{N}$ & Load cell \\
E & Impeller coupling & $\mathrm{O}$ & Recorder \\
F & Shaft & $\mathrm{P}$ & Lever Arm \\
G & Liquid level & $\mathrm{Q}$ & Gas pipe \\
$\mathrm{H}$ & Impeller & $\mathrm{R}$ & Rotameter \\
$\mathrm{I}$ & Sparger & $\mathrm{S}$ & Impeller details \\
& & & \\
\hline & & &
\end{tabular}

Table S2. Selected data from Figure 11

\begin{tabular}{ccc}
\hline $\mathrm{C}_{\mathrm{v}}(\mathrm{v} / \mathrm{v})$ & $\mathrm{Q}_{\mathrm{g}}(\mathrm{vvm})$ & Mass of the suspended solids per unit power input $(\mathrm{kg} / \mathrm{W})$ \\
\hline 0.05 & 0.5 & 1.87 \\
0.05 & 0 & 1.03 \\
\hline 0.3 & 0.5 & 3.38 \\
0.3 & 0 & 3.66 \\
\hline
\end{tabular}

The data shown in Table S2 further illustrate the relationship between the gas flow rate, solids concentration and $\varepsilon_{\mathrm{jsg}}{ }^{-1}$ values for 45PB impeller. Aeration improves the impeller power efficiency at $\mathrm{C}_{\mathrm{v}}=$ 0.05 , but leads to an opposite result for $\mathrm{C}_{\mathrm{v}}=0.3$. It can be therefore concluded that the power efficiency 
of 45PB impeller is higher with higher solid loadings in both aerated and unaerated systems. Moreover, the difference in $\varepsilon_{\mathrm{jsg}}{ }^{-1}$ values between aerated and unaerated conditions becomes smaller as $\mathrm{C}_{\mathrm{v}}$ increases (Figure 11). 


\section{Abstract Graphics}

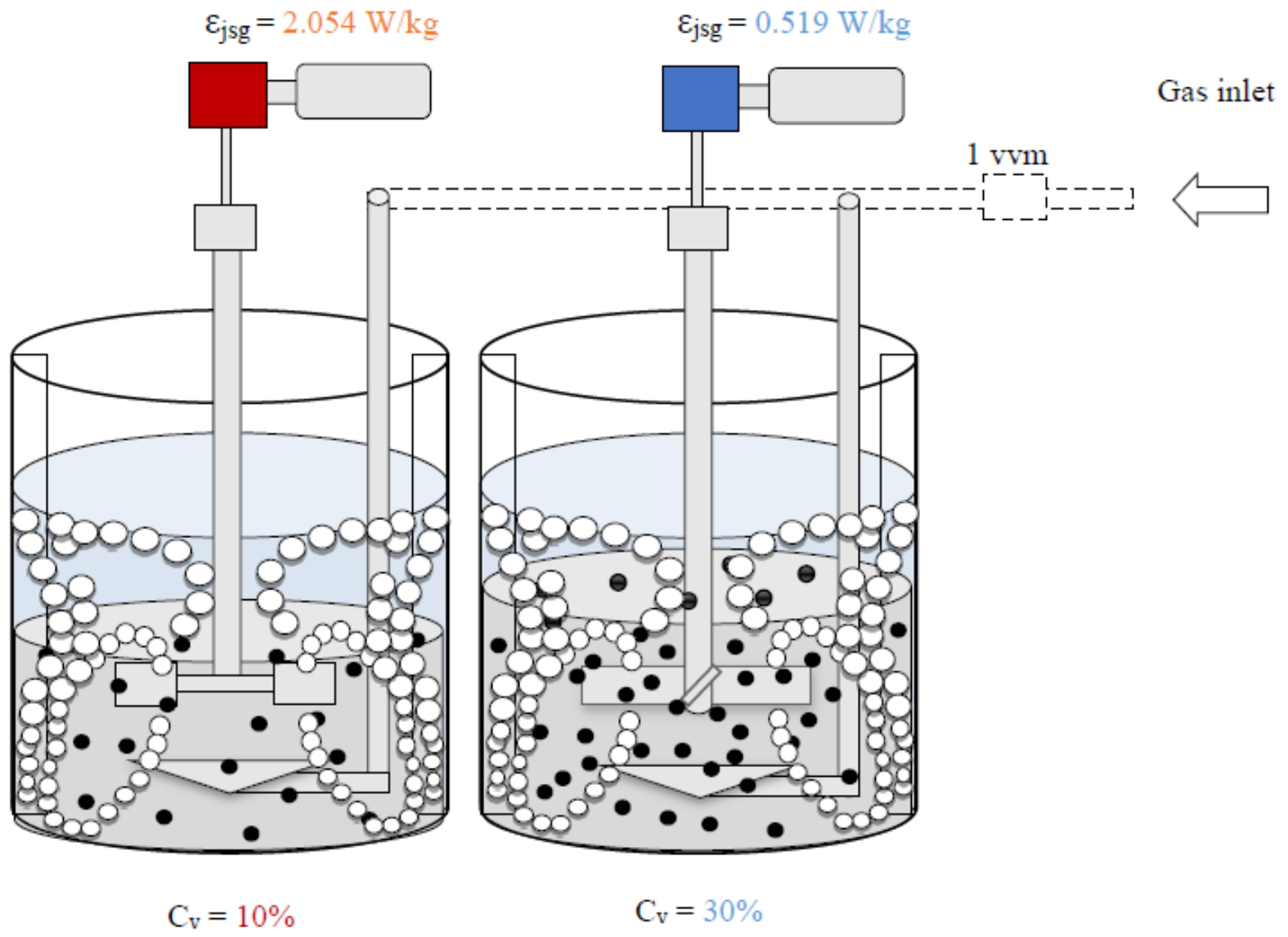

